\title{
JENIS DAN MAKNA JALAMBA (PAGAR ADAT) SEBAGAI PENCIRI IDENTITAS DAERAH GORONTALO
}

\author{
Abdi Gunawan Djafar \\ Jurusan Teknik Arsitektur, Fakultas Teknik, Universitas Negeri Gorontalo \\ abdi_djafar@ung.ac.id
}

Diterima: 29-06-2020 Direview: 07-09-2020 Direvisi : 08-10-2020 Disetujui: 15-10-2020

ABSTRAK. Indonesia dengan banyaknya suku dan budayanya kaya akan keragaman arsitekturnya. Tradisi dan budaya di tiap daerah, meskipun berbeda-beda tapi menghasilkan karya arsitekur tradisional yang ternyata memiliki benang merah antara satu dengan yang lainnya. Rumah panggung di berbagai daerah memiliki pagar pembatas pada teras atau serambi yang memiliki nilai makna, fungsi, dan keindahannya. Salah satu pagar pembatas tersebut adalah jalamba dari daerah Gorontalo yang umumnya digunakan pada upacara adat pernikahan, kedukaan, dan lain-lain. Jalamba ini juga menjadi pagar penciri identitas adat daerah-daerah di Gorontalo. Penelitian ini bertujuan untuk mengkaji lebih dalam tentang jalamba, jenis dan makna dari jalamba melalui kajian literatur, wawancara, dan pengamatan terhadap rumah panggung tempat jalamba yang digunakan saat ini. Setelah dianalisis melalui teropong sejarah dan kebudayaan, hasil penelitian menunjukkan dua dari enam jenis jalamba saat ini telah menjadi penciri identitas daerah Gorontalo.

Kata kunci: Rumah panggung, Pagar pembatas, Pola dan Ragam

ABSTRACT. Indonesia, with its many ethnic groups and cultures, is rich in architectural diversity. The traditions and culture in each region, although different, have resulted in the work of traditional architects, which have a common thread with one another. Stilt houses in various areas have a guardrail on the terrace or porch, which has a value of meaning, function, and beauty. One of the guardrails is a Jalamba from the Gorontalo area, which is generally used in traditional wedding ceremonies, grief, and others. This Jalamba is also a fence that identifies the traditional identity of areas in Gorontalo. This study aims to examine the Jalamba's types and meaning of Jalamba through literature review, interviews, and observations of the house on stilts where the Jalamba is currently used. After analyzing historical and cultural binoculars, the results showed that two of the six types of Jalamba now had become the characteristics of Gorontalo's regional identity.

Keywords: Stilt house, Railing, Pattern and Style

\section{PENDAHULUAN}

Dalam membahas arsitektur yang bercirikan daerah di Indonesia terdapat beberapa istilah yang sering ditemukan antara lain arsitektur nusantara dan arsitektur tradisional. Jika arsitektur tradisional mempelajari tentang kosmologi dan mitos, mata pencaharian, jalinan sosial, tata letak, dan lainnya, arsitektur nusantara lebih membahas tentang tatanan estetika-komposisi, sistem struktur dan konstruksi, adat-tradisi manusia-lingkunganbangunan, dan lain-lain (Sudarwani, 2017).

Penjelasan di atas menunjukkan pendekatanpendekatan untuk mengupas arsitektur di wilayah Indonesia. Sehingga sebuah objek arsitektur dapat dibahas melalui teropong arsitektur tradisional dan arsitektur nusantara. Teropong arsitektur tradisional untuk mendalami filosofi nilai budaya suatu karya arsitektur, sedangkan teropong arsitektur nusantara melihat gambaran besarnya, hubungan antara arsitektur di suatu daerah dengan daerah lainnya di nusantara.

Salah satu konsep dalam arsitektur tradisional adalah pembagian bangunan atas kepala, badan, dan kaki yang menunjukkan bagian atap, dinding/ruangan, dan tiang/pondasi/ kolong bangunan. Ini menunjukkan bagaimana rumah tradisional dibangun dengan bentuk rumah berpanggung. Konsep arsitektur nusantara adalah arsitektur sebagai pernaungan dimana atap, dinding, dan kolong dapat meneduhkan dan membuat ruang untuk bernaung di bawah dan di sekitar bangunan. Rumah berpanggung memiliki teras atau surambi yang secara tradisi menjadi ruang perantaraan bagian luar dan dalam, secara tata letak ruang ini diletakkan sebelum pintu masuk agar pemilik bangunan dapat menyadari adanya tamu yang datang. Arsitektur nusantara mengangkat ruang serambi sebagai satu kesempatan untuk bersolek, menjadi elemen daya tarik dari 
bangunan dengan memberikan ornamenornamen pada ruangan tersebut.

Arsitektur nusantara kaya akan bentuk dan ornamen-ornamen pada rumah berpanggung. Salah satu bagian dari rumah panggung berornamen adalah pagar pembatas pada teras/serambi. Berada di ketinggian menyebabkan teras rumah panggung perlu dilindungi dengan pagar pembatas agar pengguna bangunan dapat mengenali batas ruangan dan mencegah agar tidak terjatuh ke bawah.

Pagar pembatas ini bahkan memiliki sebutan dan bentuk ornamen yang unik dalam daerahdaerah di nusantara. Di daerah Gorontalo, terdapat pagar yang disebut Jalamba, digunakan secara temporer pada upacara adat dan digunakan secara permanen pada rumahrumah panggung. Pagar ini memiliki beberapa ragam ornamen dengan fungsi yang berbedabeda (Daulima \& Pateda, 2004).

Di sebelah Timur dari daerah Gorontalo terdapat suku Bolaang Mongondow yang juga memiliki pagar rumah panggung yang bernama Tondok in Gandaria, yaitu pagar (Tondok) yang mengelilingi ruangan yang disebut Gandaria yang berfungsi untuk menerima tamu (Bahansubu, 2017).

Daerah Palembang memiliki rumah Limas dengan pagar bernama Tenggalung yang sangat rapat sehingga membentuk kisi-kisi dan memungkinkan penghuni rumah untuk memantau sekeliling rumahnya dengan tetap menjaga privasi pemilik rumah (Rakhman, 2015).

Rumah Bubungan Tinggi di Kalimantan Selatan memiliki pagar di palataran/surambi bernama Kandang Rasi berupa susunan papan dengan ukiran bernama kembang Bogam atau dengan ukiran bermotif geometris (Mentayani \& Andini, 2007).

Pagar rumah panggung juga telah menjadi ciri arsitektur tradisional Melayu, dimana salah satu dari 16 elemen estetika dalam mengidentifikasi karya arsitektur tradisional Melayu adalah keberadaan pagar musang (Yusoff et al., 2010).

Keberadaan pagar pada rumah panggung tidak lepas dari keberadaan rumah panggung itu sendiri. Dengan perubahan zaman, pemilik rumah-rumah panggung ini mulai melakukan perubahan untuk menyesuaikan hunian mereka dengan perubahan gaya arsitektur yang terjadi, yaitu dengan mengubah material bangunan. Contohnya dengan menggunakan material besi pada pagar pembatas di legolego (teras) pada rumah panggung di Sulawesi Selatan (Beddu et al., 2018). Demikian halnya pada rumah tradisional Betawi, dimana pagar pembatas yang disebut Langkan diberi tambahan besi berbentuk geometris (Wijayanti et al., 2019).

Pagar pembatas pada teras rumah-rumah panggung di nusantara memiliki unsur-unsur tangible dan intangible yang menunjukkan kekayaan kebudayaan nusantara.

Literatur dan penelitian yang ada kebanyakan membahas rumah panggung sebagai objek utamanya dan pagar rumah panggung sebagai bagian yang melengkapi rumah panggung tersebut.

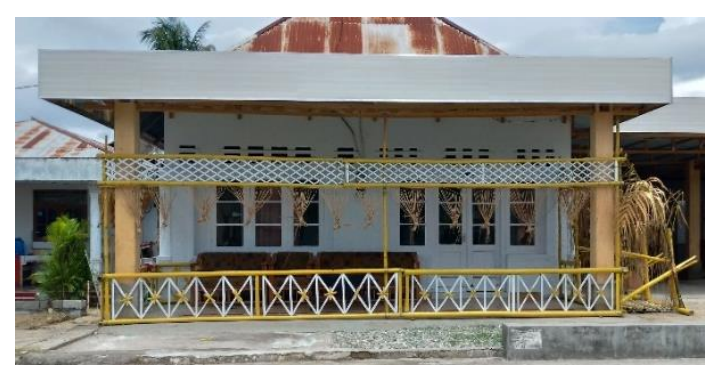

Gambar 1. Jalamba temporer berbahan bambu pada teras rumah yang digunakan ketika adat pernikahan

(Sumber: Dokumentasi Pribadi, 2018)

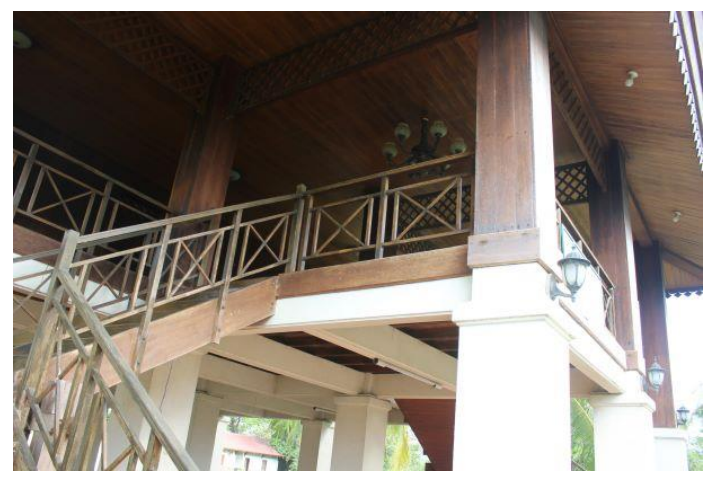

Gambar 2. Jalamba permanen berbahan kayu pada teras dan tangga pada bangunan tradisional Dulohupa

(Sumber: Dokumentasi Pribadi, 2015)

Penelitian ini akan membahas tentang jalamba, pagar adat di daerah Gorontalo yang sering digunakan pada upacara adat seperti pernikahan dan kedukaan namun terbatas pada beberapa ragam saja. Satu-satunya literatur tertulis tentang jalamba menyebutkan adanya beberapa ragam jalamba yang sudah 
sulit ditemukan di masa kini, namun perlu untuk dibahas dalam upaya untuk menghidupkan kembali kekayaan arsitektur Gorontalo. Keragaman jalamba perlu untuk ditelusuri, dipublikasikan agar lebih dikenal banyak orang, dilestarikan, serta dikembangkan agar dapat diterapkan pada bangunan moderen.

\section{METODE PENELITIAN}

Penelitian ini merupakan penelitian kualitatif deskriptif. Data diambil melalui kajian literatur, wawancara, dan pengamatan di lapangan. Literatur yang dikaji didapatkan melalui buku, artikel internet, dan jurnal penelitian. Keragaman jalamba yang disebutkan dalam literatur tertulis akan dipaparkan secara lebih luas. Data yang didapatkan melalui seluruh sumber akan diperbandingkan untuk menjelaskan keadaan penggunaan jalamba saat ini. Analisis sejarah dan kebudayaan digunakan untuk menjelaskan jalamba yang menjadi penciri daerah Gorontalo.

\section{HASIL DAN PEMBAHASAN}

\section{Penamaan}

Jalamba adalah nama untuk pagar adat yang selama ini telah banyak dikenal oleh masyarakat Gorontalo. Namun dalam bahasa Gorontalo asli, pagar adat yang sebenarnya bernama toyidu (Daulima, 2008).

\section{Fungsi}

Jalamba berfungsi sebagai pagar yang melindungi pengguna bangunan agar tidak melampaui batas dari tepian teras rumah panggung. Pada upacara adat pernikahan budaya Gorontalo, jalamba menjadi sebuah konstruksi yang diperlukan, dimana di teras harus disediakan bulita atau tempat duduk bagi pemimpin masyarakat/ daerah, tokoh agama, dan tokoh adat, dengan jalamba menjadi pagar yang melindungi ruangan mereka.

Jalamba yang diletakkan di sepanjang tepian teras atau serambi memiliki satu segmen terbuka tempat tangga diletakkan, sehingga hanya ada satu pintu/ akses dari bawah (ketinggian tanah) untuk sampai ke teras.Pada rumah panggung jalamba menjadi bagian yang harus ada, namun pada rumah tak berpanggung yang memiliki ketinggian teras yang rendah dan tidak menggunakan jalamba maka ketika akan mengadakan upacara adat (misalnya pernikahan), dibuatlah jalamba dengan bambu khususnya bambu kuning yang memiliki nilai budaya. Beberapa hari setelah kegiatan adat selesai, jalamba bambu dibongkar. Hal ini berpengaruh pada penggunaan material untuk jalamba. Untuk konstruksi permanen pada rumah berpanggung bahan yang digunakan berupa kayu olahan dengan potongan yang rapi dan diberi finishing, sedangkan untuk konstruksi temporer dapat menggunakan material yang mudah terjangkau, dibangun, dan tanpa perlu difinishing.

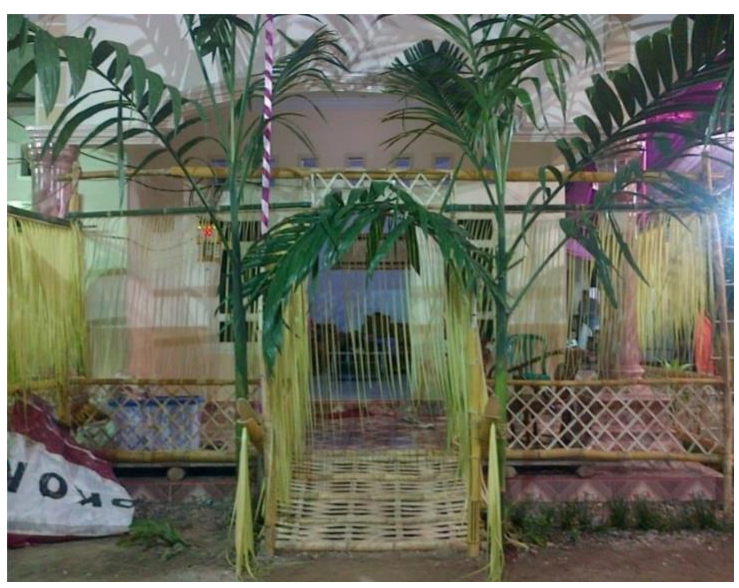

Gambar 3. Teras rumah yang dikelilingi jalamba bambu dan pintu masuk di tengahnya Sumber: (Pasue et al., 2013)

Sebuah masjid yang dikelola oleh ketua adat kota Gorontalo menggunakan jalamba sebagai pagar pembatas pada selasarnya. Hal ini merupakan langkah yang diambil untuk melestarikan budaya Gorontalo sekaligus menunjukkan bahwa jalamba dapat digunakan pada bangunan peribadatan.

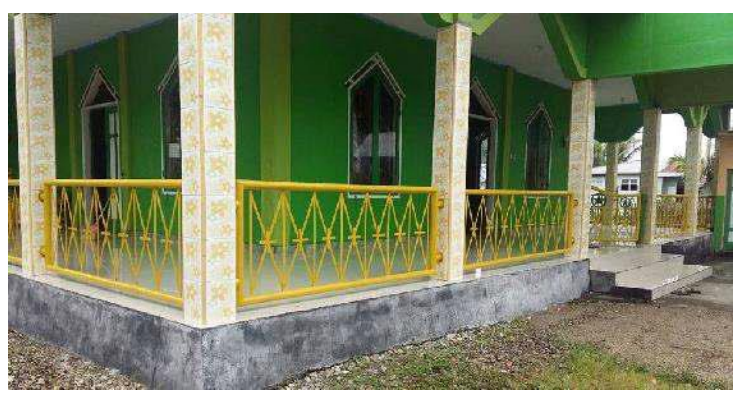

Gambar 4 Jalamba permanen berbahan besi pada teras masjid

(Sumber: Dokumentasi Pribadi, 2017)

\section{Jenis dan Ragam Jalamba}

Jenis-jenis jalamba berdasarkan buku Daulima dijelaskan melalui tabel 1 dan digambarkan pada gambar 5 hingga gambar 10 . 
Tabel 1. Jenis-jenis jalamba

\begin{tabular}{|c|c|c|c|}
\hline No & Jenis & Pengguna & Penggunaan \\
\hline 1 & $\begin{array}{l}\text { Mohimato } \\
\text { lo unggu }\end{array}$ & $\begin{array}{c}\text { Masyarakat } \\
\text { biasa }\end{array}$ & $\begin{array}{c}\text { Digunakan } \\
\text { ketika hajatan }\end{array}$ \\
\hline 2 & Pobiya & $\begin{array}{l}\text { Semua } \\
\text { golongan }\end{array}$ & $\begin{array}{c}\text { Digunakan } \\
\text { ketika pesta } \\
\text { rakyat }\end{array}$ \\
\hline 3 & Ungala'a & $\begin{array}{l}\text { Pejabat } \\
\text { kerajaan }\end{array}$ & $\begin{array}{l}\text { Digunakan } \\
\text { ketika hajatan }\end{array}$ \\
\hline 4 & Pakadanga & $\begin{array}{l}\text { Pemimpin } \\
\text { daerah }\end{array}$ & $\begin{array}{c}\text { Digunakan } \\
\text { pada rumah }\end{array}$ \\
\hline 5 & Wolihi & Raja & $\begin{array}{l}\text { Digunakan } \\
\text { pada rumah }\end{array}$ \\
\hline 6 & Layahu & $\begin{array}{l}\text { Semua } \\
\text { golongan }\end{array}$ & $\begin{array}{c}\text { Digunakan } \\
\text { ketika ada } \\
\text { hajatan yang } \\
\text { bercampur } \\
\text { dengan adat } \\
\text { dari daerah } \\
\text { lain }\end{array}$ \\
\hline
\end{tabular}

Sumber : (Daulima, 2008)

Dari keterangan literatur ini dapat dipelajari bahwa jalamba memiliki ketentuan tentang pengkhususan penggunanya yang dapat dibagi atas beberapa golongan sosial dan waktu penggunaannya yang dapat dibagi atas temporer (ada hajatan) dan permanen.

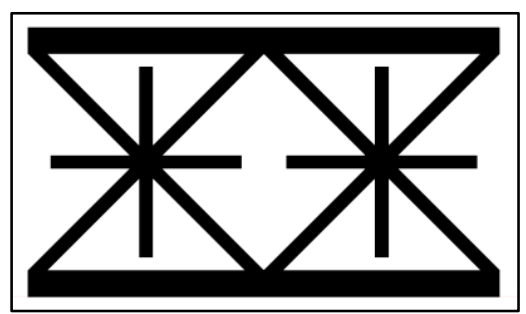

Gambar 5. Jalamba Mohimato lo unggu Sumber: (Daulima, 2008)

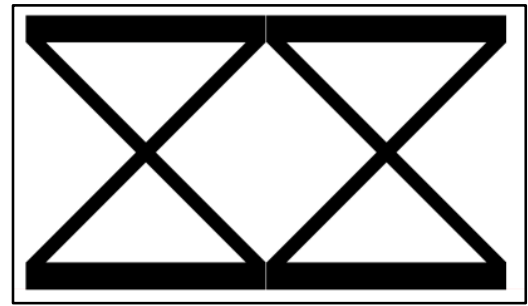

Gambar 6. Jalamba Pobiya

Sumber: (Daulima, 2008)

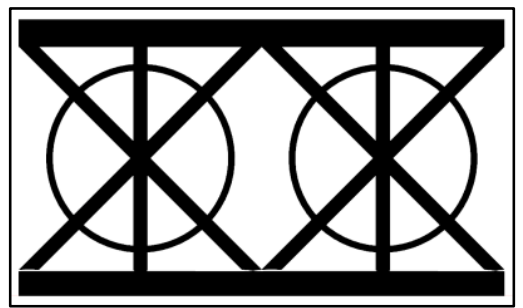

Gambar 7. Jalamba Ungala'a

((Sumber: Interpretasi penulis terhadap deskripsi dalam buku (Daulima, 2008)

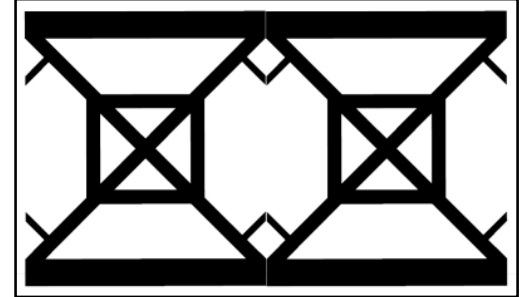

Gambar 8. Jalamba Pakadanga

Sumber: (Daulima, 2008)

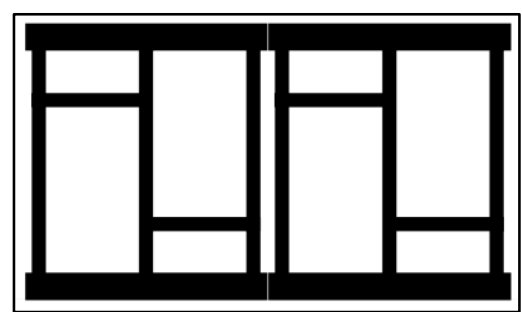

Gambar 9. Jalamba Wolihi

Sumber: (Daulima, 2008)

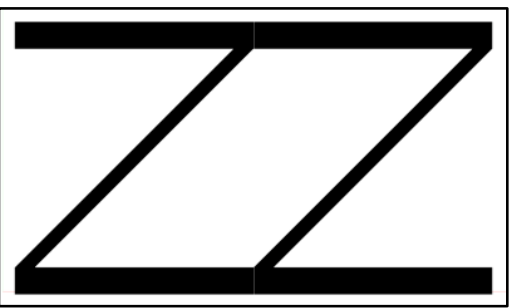

Gambar 10. Jalamba Layahu

(Sumber: Interpretasi penulis terhadap deskripsi dalam buku (Daulima, 2008)

Dari 6 jenis jalamba, terdapat 4 jenis jalamba yang digunakan oleh 4 golongan adat yang berlaku di Gorontalo. Sejak terbentuknya kerajaan, masyarakat Gorontalo terbagi atas beberapa golongan dan pembagian golongan ini telah mengalami beberapa kali perubahan. Pada akhir masa pemerintahan Belanda, masyarakat Gorontalo hanya terbagi atas 4 golongan yakni golongan tuwango lipu atau masyarakat biasa, golongan wali-wali atau pejabat kerajaan, golongan udula'a atau pemimpin kampung/ daerah serta golongan mongo'eya atau para bangsawan/ raja (Daulima \& Pateda, 2004). Dua jenis jalamba digunakan ketika ada hajatan yang meliputi pesta rakyat dan yang melibatkan pencampuran golongan dan adat budaya dari berbagai daerah. Belum ditemukan literatur atau informasi yang menyebutkan jenis pesta rakyat seperti apa yang dalam pelaksanaannya menggunakan jalamba pobiya dan pada bangunan berjenis apa (rumah atau bangunan pernaungan umum).

Kedua jenis jalamba yang digunakan oleh pemimpin daerah dan raja dipasang pada 
rumah dan menggambarkan bahwa rumah yang dimaksud adalah rumah yang memiliki teras untuk diletakkan jalamba. Sedangkan jalamba untuk golongan masyarakat biasa dan pejabat kerajaan hanya dipasang ketika hajatan dan menyiratkan bahwa bangunan rumahnya tidak memiliki teras yang menjadi bagian utuh bersama badan rumahnya. Penggunaan jalamba dengan cara temporer ini masih dilakukan hingga saat ini dimana pada rumah yang hanya memiliki teras yang kecil ketika hajatan pada halamannya akan dihamparkan konstruksi lantai papan dengan ganjalan kayu sehingga terasnya menjadi lebih luas dan sama tinggi dengan ruang dalam rumahnya kemudian setelah selesai dipasang jalamba pada tepian lantainya.

Saat ini dari keenam jalamba yang disebutkan di atas hanya ada 3 jalamba yang masih dapat ditemukan penggunaannya pada rumah panggung di Gorontalo. Namun bentuknya tidak mirip sepenuhnya dengan yang digambarkan di buku. Berdasarkan wawancara, masyarakat Gorontalo kurang mengetahui jenis-jenis jalamba yang ada pada rumah panggung, dan bentuk ornamen yang ada pada rumah panggung tidak bisa menjadi acuan dalam menentukan tingkatan/golongan sosial masyarakat sebagaimana penjelasan dalam buku dimana dengan melihat jalamba sebagai elemen fasad dapat langsung membedakan golongan pengguna bangunan itu (Abdul, 2010). Tidak adanya bangunan peninggalan raja-raja Gorontalo zaman dulu semakin mempersulit pencarian keberadaan jalamba khususnya jalamba wolihi.

Penggunaan elemen arsitektur yang dibedakan atas golongan atau strata sosial ini juga dapat dijumpai pada arsitektur bangunanbangunan di nusantara. Contohnya arsitektur tradisional Mamasa di Sulawesi Barat, dimana rumah penduduk yang tergolong Tana'Bulawan atau golongan tertinggi memiliki ukiran-ukiran simbolik pada dinding depan rumah sedangkan pada rumah golongan masyarakat biasa atau Tana'Karurung, rumahnya yang tidak memiliki ukiran (Ansaar, 2011). Sedangkan di Bali, rumah-rumah terbagi atas 4 macam sesuai golongannya. Yakni Puri untuk golongan Brahmana (yang tertinggi), Griya untuk golongan Ksatria, Jero untuk golongan Wesia, dan Umah untuk golongan Sudra (yang terendah). Ukuran rumah untuk golongan Sudra (rendah) jauh lebih kecil dari rumah untuk golongangolongan di atasnya, begitupun dengan ruangan-ruangan di dalamnya memiliki jenis yang lebih sedikit (NusaBali, 2019).
Saat ini, masyarakat Gorontalo tidak lagi mengenal ke 4 strata sosial yang dulu digunakan. Perubahan ini diperkirakan memiliki dampak terhadap penggunaan jalamba yang dibedakan atas golongan sosial masyarakat.

Selain jalamba yang disebutkan di atas, berdasarkan wawancara dengan ketua adat daerah Hulontalo, terdapat penggunaan jalamba yang lebih populer dan terus dipakai hingga saat ini yaitu jalamba yang digunakan sebagai penanda/ identitas daerah adat. Sebagai identitas dari 2 kerajaan besar di provinsi Gorontalo, kerajaan Hulontalo (Gorontalo) dan Limutu (Limboto). Kedua kerajaan memiliki jalamba untuk menandakan daerah adatnya masing-masing. Tanpa mengenal golongan, baik masyarakat dan pejabat daerah yang tinggal di wilayah adat Hulontalo menggunakan jalamba penanda adat Hulontalo ketika melakukan hajatan atau bahkan ketika menggunakan jalamba sebagai ornamen permanen pada bangunannya. Begitu juga untuk wilayah adat Limutu, tanpa mengenal golongan pula, masyarakatnya menggunakan jalamba penanda adat Limutu.

Kedua jalamba sama pola dan ragamnya namun berkebalikan dalam penempatannya. Dalam penggunaannya, 2 pola jalamba digunakan sekaligus. Pola 1 diletakkan di atas (bawah langit-langit), dan pola 2 diletakkan di bawah (atas lantai). Salah satu polanya adalah pola mohimato lo unggu, sedangkan pola lainnya mirip dengan jalamba pobiya namun lebih banyak material yang digunakan dengan jarak yang lebih rapat. Untuk jalamba adat Hulontalo, pola mohimato lo unggu diletakkan di bawah dan pasangannya diletakkan di atas seperti ditunjukkan dengan foto pada gambar 1,2, dan 4. Gambar sederhana ditunjukkan pada gambar 11. Sedangkan untuk jalamba Limutu, pola mohimato lo unggu diletakkan di atas, dan pasangannya di bagian bawah seperti ditunjukkan pada gambar 3. Gambar sederhananya ditunjukkan pada gambar 12 .

Jalamba menjadi contoh penciptaan identitas sebuah tempat dengan menggunakan bentukbentuk yang dapat mencirikan etnis kedaerahan. Ketika melihat sebuah jalamba terpasang, tanpa perlu mengecek atau menanyakan identitas geografis atau administrasi sebuah daerah, masyarakat dapat mengenali adat budaya yang berlaku di daerah tersebut. Dan sebaliknya, bila terjadi kesalahan dalam pemasangan jalamba masyarakat harusnya dapat mengenali adanya 
kekeliruan atau pelanggaran dalam pelaksanaan suatu upacara adat.

\section{Makna}

Jalamba memberikan penjelasan atas identitas golongan sosial yang dimiliki seseorang di daerah Gorontalo. Setiap golongan memiliki hak dan kewajibannya untuk mencegah golongan atas melakukan kesewenangwenangan terhadap golongan di bawahnya (Daulima et al, 2004). Sehingga penggunaan jalamba bukanlah suatu aib bagi golongan sosial bawah atau kebanggaan bagi golongan sosial atas. Untuk golongan raja dan pemimpin daerah, jalamba nampak pada bangunannya, sedangkan untuk golongan pejabat kerajaan dan masyarakat biasa, jalamba hanya digunakan ketika melakukan hajatan.

Diantara bentuk jalamba-jalamba, hanya jalamba ungala'a yang memiliki bentuk lingkaran. Ungala'a dalam bahasa Gorontalo berarti kekerabatan dan bentuk lingkaran menunjukkan hubungan kekerabatan antara individu. Jalamba yang berbentuk lingkaran menandakan bahwa dahulu telah digunakan teknik bubut untuk membentuk ulir lingkaran. Sekitar tahun 1890an telah dimungkinkan adanya teknologi bubut untuk membuat motif yang sama dan sebangun (Adiatmono et al., 2013).

Pakadanga adalah istilah yang dapat ditemukan dalam 3 bagian pada bangunan rumah Gorontalo yaitu pada dekorasi (di atas) pintu (Schroder, 1908), lisplang, dan pagar pembatas (jalamba). Pakadanga merupakan ornamen / dekorasi yang diaplikasikan di bagian tengah (badan) bangunan dan menjadi daya tarik bangunan itu (Adiatmono, 2017). Penggunaan istilah pakadanga sebagai ornamen lisplang menunjukkan bahwa penerapannya pada bangunan tidak hanya di bagian tengah, tapi juga hingga ke bagian atas (atap) bangunan. Pada lisplang, bentuk ornamen pakadanga berupa rangkaian orang berantai yang bermakna lambang persatuan dalam masyarakat (Asri \& Abdul, 2015).

Wolihi dalam bahasa Gorontalo berarti tiang, sehingga jalamba wolihi yang digunakan pada rumah raja menunjukkan peran raja sebagai tiang yang menjadi tumpuan untuk melindungi dan menjaga kerajaan serta rakyatnya. Pola wolihi memiliki bagian tegak dan datar. Bagian tegak dapat diibaratkan sebagai tiang-tiang sedangkan bagian datar sebagai balok-balok yang saling mengikat dan memperkokoh tiangtiang.

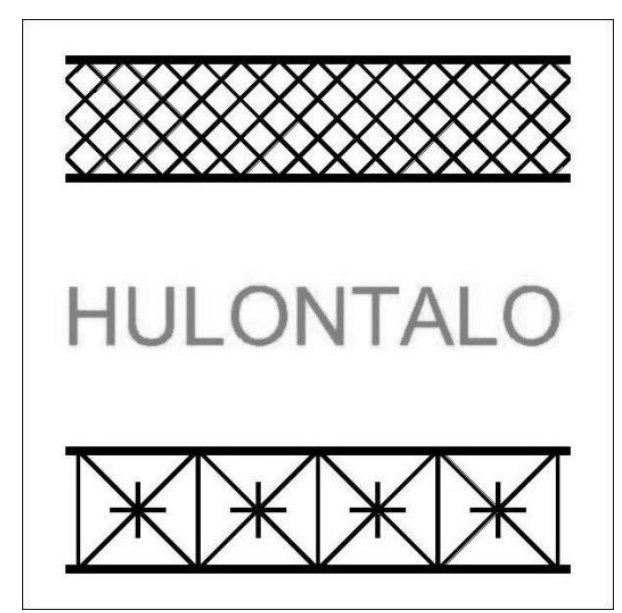

Gambar 11. Jalamba penanda daerah adat Hulontalo

(Sumber: Dokumentasi pribadi)

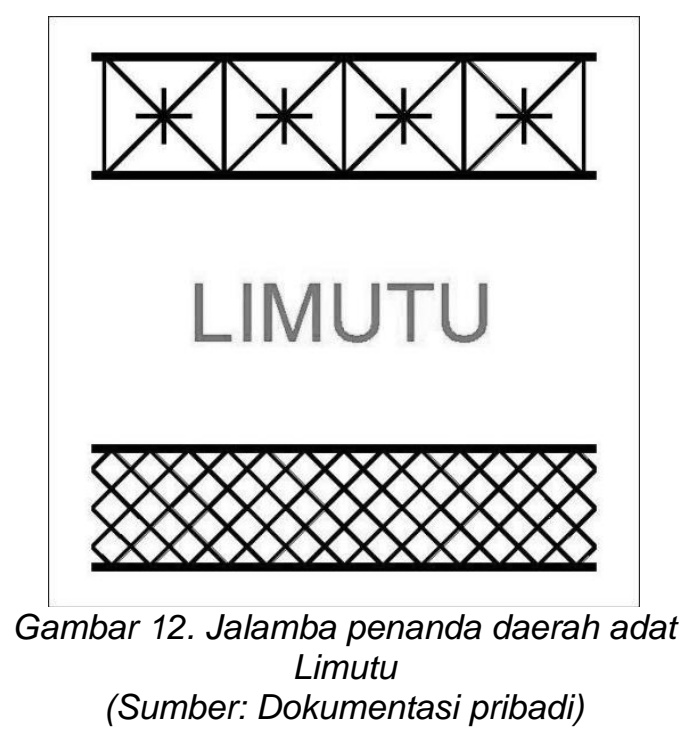

Layahu dalam bahasa Gorontalo berarti layar yang digunakan pada perahu/ kapal. Jalamba layahu digunakan untuk hajatan dimana terjadi pencampuran adat dari berbagai daerah atau adanya orang dari daerah lain yang datang di wilayah Gorontalo dan melakukan hajatan bersama. Layar yang dimaksud adalah layar kapal yang digunakan sebagai kendaraan bagi pendatang untuk mencapai daerah Gorontalo, dimana kapal merupakan moda transportasi utama untuk melakukan perjalanan jarak jauh saat itu.

Pola jalamba pobiya yang lebih rapat yang digunakan pada jalamba penanda daerah adat memiliki ketentuan khusus terkait jumlah lubang pada 1 baris tegaknya. Dimana jumlah persilangan garis-garis miring pada pola itu harus menghasilkan 3 buah lubang yang memberi makna 3 tali temali pemerintahan yang terdiri atas eksekutif (buwatula bubato); 
pembesar negeri, legislatif (buwatulo bantayo), tokoh adat, dan syara' (buwatulo syara') mewakili imam, hakim, kadhi (Heryati \& Nico Abdul, 2014).

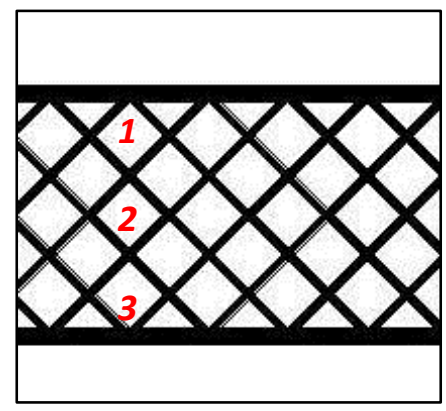

Gambar 13. Tiga lubang persegi/jajar genjang pada jalamba penanda daerah adat

(Sumber: Dokumentasi pribadi)

\section{Pengaruh Asing Pada Bentukan Ornamen}

Setelah mengalami krisis di pertengahan abad 19, daerah Gorontalo kemudian mengalami pemulihan ekonominya pada tahun 1890 dengan kedatangan orang Eropa. Kemudian mereka membangun rumah-rumah di Gorontalo dengan cara cara akulturasi kebudayaan. Selain orang Eropa, masyarakat Ternate, Cina, dan Arab juga datang di wilayah Gorontalo. Dengan banyaknya budaya yang datang, masyarakat Gorontalo berusaha melestarikan agar ornamen-ornamen tradisionalnya tetap muncul pada rumah yang terbangun. Bentuk dan motif ornamen pada rumah tradisional di Gorontalo telah mendapat pengaruh dari budaya-budaya tersebut (Adiatmono, 2017).

\section{Konstruksi}

Konstruksi jalamba terdiri atas 4 bagian yaitu palang atas, palang bawah, tiang, dan pola jalamba di bagian tengah.

Jalamba berbahan bambu dibuat menggunakan gelondong bambu yang dipotong-potong untuk dijadikan palangpalang, dan tiangnya. Sedangkan untuk bagian tengah jalamba, bambu dibelah jadi beberapa bagian kemudian dikeluarkan kulitnya menyisakan permukaannya yang berwarna putih untuk dirangkai membuat pola jalamba. Pada palang dibuatkan lubanglubang untuk memasukkan rangkaian belahanbelahan bambu. Untuk membuat jalamba Pobiya sebagai penanda daerah adat, maka lubang pada sebuah palang dihubungkan dengan lubang ke 4 pada palang lainnya agar mendapatkan pola 3 lubang persegi/jajar genjang.

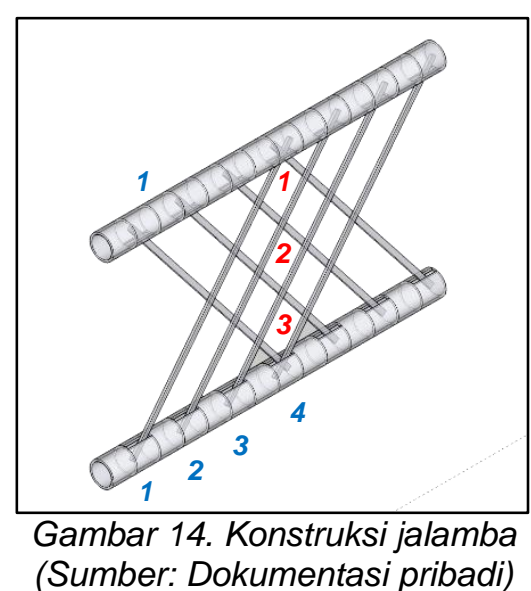

\section{Studi Kasus Rumah Panggung}

Berdasarkan penelitian-penelitian yang telah dilakukan sebelumnya (Abdul, 2010; Heryati, 2011), dapat ditemukan kesamaan pada bentuk-bentuk jalamba pada rumah panggung yang menjadi objek penelitian. Jalamba yang digunakan sebagian besar hanya diletakkan di atas lantai (tidak ada yang diletakkan dekat plafon) dan hanya terdapat 2 jalamba diantara 6 jalamba yang disebutkan dalam literatur yang ditulis Daulima. Ditemukan juga rumah panggung yang menggunakan pagar dengan pola berbentuk gaya khas kolonial.

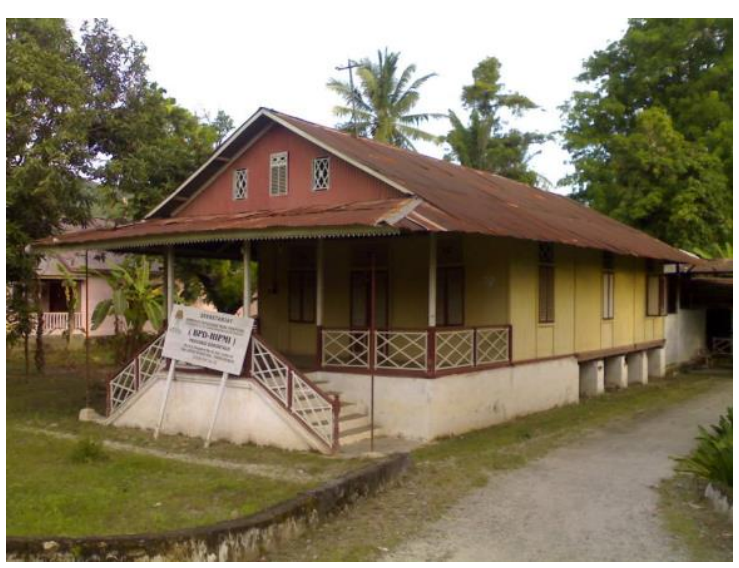

Gambar 15. Rumah panggung menggunakan jalamba pobiya

Sumber: (Heryati, 2011)

Bentuk jalamba yang digunakan pada rumahrumah panggung ini adalah jalamba mohimato lo unggu dan jalamba pobiya. Kedua jenis jalamba ini adalah jalamba yang juga digunakan sebagai penanda/ identitas daerah adat Hulontalo dan Limutu. Dimana daerah administrasi kerajaan Hulontalo menggunakan jalamba mohimato lo unggu pada level lantai sedangkan jalamba yang digunakan pada daerah Limutu menggunakan jalamba pobiya pada level lantainya. 


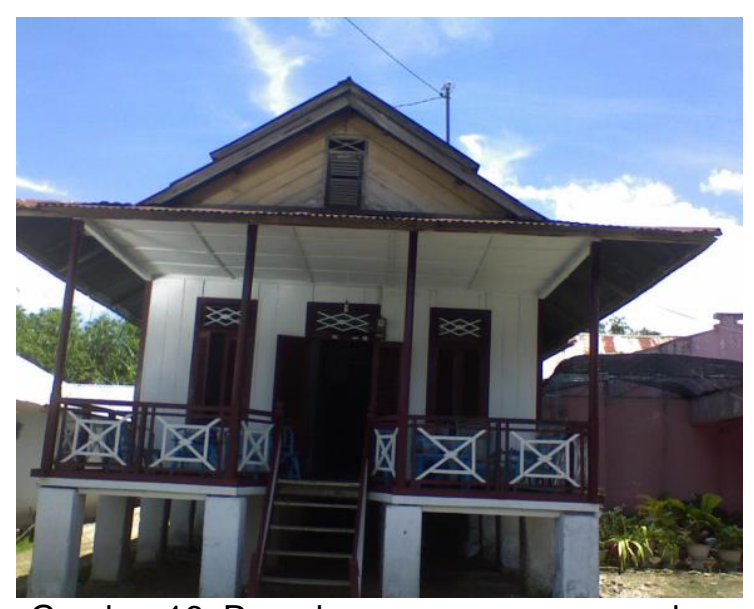

Gambar 16. Rumah panggung menggunakan jalamba mohimato lo unggu Sumber: (Heryati, 2011)

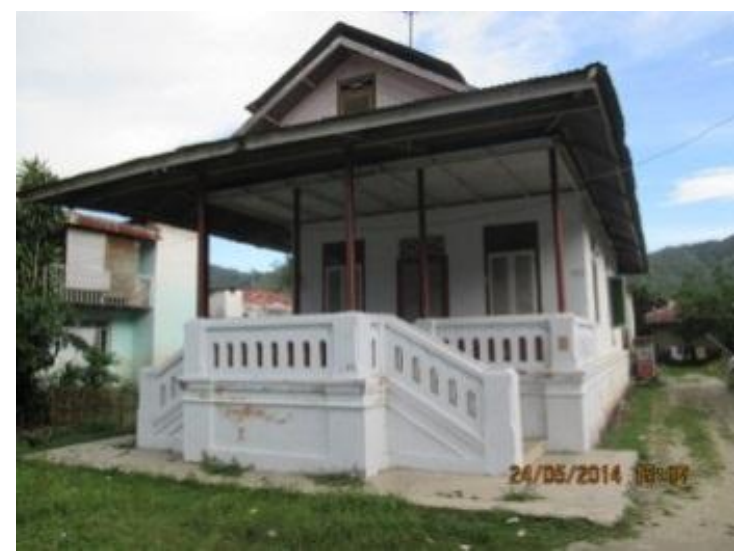

Gambar 17. Rumah panggung dengan pagar tepian bergaya kolonial

Sumber: (Heryati \& Nico Abdul, 2014)

Dalam literatur tertulis tidak menyebutkan tentang jalamba yang berfungsi sebagai penanda identitas daerah, melainkan tentang jalamba yang digunakan oleh berbagai lapisan sosial dalam masyarakat pada jaman dimana kerajaan-kerajaan setempat masih berdiri. Pada akhir abad ke 19, kerajaan-kerajaan di Gorontalo dibubarkan oleh Belanda sehingga secara otomatis menghapus perbedaan status pada masyarakatnya. Pada studi banding yang dilakukan terhadap rumah-rumah panggung yang dibangun di abad ke 20 ini, hanya ditemukan 2 jenis jalamba yang juga telah dijelaskan dalam buku tersebut. Sedangkan bentuk-bentuk lainnya tidak lagi ditemukan.

Dari segi makna dan cara penggunaannya, baik jalamba mohimato lo unggu dan jalamba pobiya adalah jalamba yang digunakan ketika berlangsung hajatan dan pesta rakyat. Keduanya bermakna terbuka dan mengundang bagi masyarakat untuk datang. Aktifitas pada tempat yang menggunakannya juga bersifat publik/ umum sehingga jalamba ini dapat digunakan oleh siapapun. Terlebih dengan tiadanya pemisahan status sosial dalam masyarakat, maka tak hanya masyarakat biasa, pejabat daerah pun dapat menggunakan kedua bentuk jalamba ini.

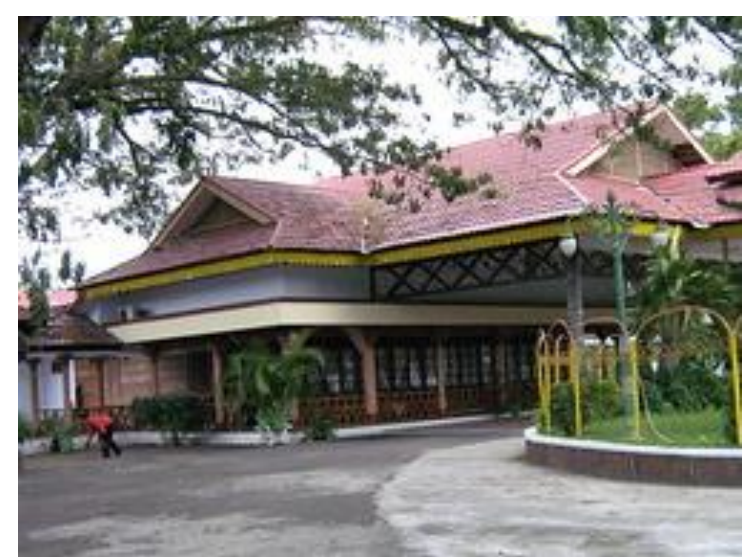

Gambar 18. Jalamba mohimato lo unggu dan pobiya dipasang pada rumah dinas walikota Gorontalo

(Sumber: flickr iman noer adi)

\section{KESIMPULAN}

Jalamba lebih banyak dikenal masyarakat Gorontalo sebagai konstruksi yang digunakan pada upacara adat misalnya pernikahan, kedukaan, pengangkatan pejabat dan lain-lain.

Terdapat beragam bentuk jalamba, tiap bentuk memiliki pengkhususan pengguna berdasarkan golongan masyarakat serta tata cara penggunaannya. Bentuk jalamba mendapatkan pengaruh dari kebudayaan asing yang masuk di wilayah Gorontalo. Hilangnya sistem strata sosial dalam masyarakat diperkirakan menjadi penyebab hilangnya penggunaan beberapa ragam jalamba yang dijelaskan Daulima.

Bentuk jalamba yang saat ini lebih populer digunakan adalah jalamba mohimato lo unggu dan jalamba pobiya dimana keduanya merupakan penanda identitas daerah, khususnya wilayah adat Hulontalo dan wilayah adat Limutu. Kedua bentuk jalamba ini telah menjadi dua pilihan utama bagi penduduk daerah Gorontalo dalam memasang ornamen pada upacara adat yang diselenggarakan. Makna keduanya adalah terbuka sehingga sesuai dengan cara penggunaannya dalam menerima tamu yang datang pada upacara tersebut. Kedua jalamba ini telah, sedang, dan akan terus digunakan sebagai bagian dari budaya Gorontalo sehingga menjadi ciri identitas daerah Gorontalo. 


\section{UCAPAN TERIMA KASIH}

Terima kasih kepada Lembaga Penelitian dan Pengabdian Masyarakat Universitas Negeri Gorontalo yang telah mendanai penelitian dengan judul Jenis dan Makna Jalamba (Pagar Adat) Sebagai Penciri Identitas Daerah Gorontalo sesuai dengan surat kontrak penelitian nomor B/125/UN.47/D1/PT.01.03/2020.

\section{DAFTAR PUSTAKA}

Abdul, N. N. (2010). Karakteristik Rumah Budel Sebagai Arsitektur Vernakular Gorontalo (Era 1890-an sampai 1930an). INOVASI, 7(1), 1-15.

Adiatmono, F. (2017). The Ornament Of Gorontalo Traditional Houses: Aesthetic And Symbolic Study. Conference on Education and Cultural Heritage. Brussels.

Adiatmono, F. ... Simatupang, L. L. (2013). Identitas Ornamen Rumah Tradisional Gorontalo Tahun 1890-2001. ATRAT: Jurnal Seni Rupa, 1(2), 30-49.

Ansaar. (2011). Arsitektur Tradisional Daerah Mamasa. Direktorat Jendral Kebudayaan.

Asri, A., \& Abdul, N. N. (2015). Urgensi Penerapan Arsitektur Rumah Budel Ke Arsitektur Masa Kini Di Gorontalo. Prosiding Warisan Arsitektur Gorontalo. Ideas Publishing.

Bahansubu, H. (2017). Menyelusuri Arsitektur Bolaang Mongondow. Retrieved June 20, 2020, from http://mongondow.com/menyelusuriarsitektur-bolaang-mongondow/

Beddu, S. ... Ishak, R. A. (2018). RUMAH PANGGUNG BUGIS DI SULAWESI SELATAN ( Studi tentang Perubahan Bentuk Lego-Lego atau Teras ). Prosiding Seminar IImiah Nasional Sains Dan Teknologi Ke-4, 4(November), 2534.

Daulima, F. (2008). Dialog tentang Budaya Daerah bersama Bunda Farha $D$. Gorontalo: Galeri Budaya LSM Mbui Bungale.

Daulima, F., \& Pateda, K. (2004). Banthayo Pobo'ide Struktur \& Fungsinya. Gorontalo: Forum Suara Perempuan LSM Mbu'i Bungale.

Heryati. (2011). Nilai-nilai Sejarah dan Filosofi Pada Arsitektur Rumah Panggung Masyarakat Gorontalo. INOVASI, 8(2).

Heryati, H., \& Nico Abdul, N. (2014). KEARIFAN LOKAL PADA ARSITEKTUR VERNAKULAR GORONTALO: Tinjauan Pada Aspek Budaya dan Nilai-nilai Islam.
EI-HARAKAH (TERAKREDITASI), 16(2), 151.

https://doi.org/10.18860/el.v16i2.2774

Mentayani, I., \& Andini, D. N. (2007). Tipologi dan Morfologi Arsitektur Suku Banjar di Kal-Sel. INFO TEKNIK, 8(2), 114-122.

NusaBali. (2019). Tak Lagi Hanya di Griya dan Puri Gedong Gunung Rata Jadi Trend Orang Bali. Retrieved June 27, 2020, from

https://www.nusabali.com/berita/62115/ta k-lagi-hanya-di-griya-dan-puri

Pasue, H. ... Hasdiana. (2013). Kajian Bentuk Ngango Lo Huwayo Pada Upacara Adat Gorontalo. E-Jurnal Universitas Negeri Gorontalo.

Rakhman, A. (2015). Arti Simbolis Di Balik Ornamen Rumah Limas Palembang. ORNAMEN Jurnal Kriya, 12(1). Retrieved from

http://library1.nida.ac.th/termpaper6/sd/2 554/19755.pdf

Schroder, E. (1908). Gorontalosche Woordenlijst. S-Gravenhage: Martinus Nijhoff.

Sudarwani, M. M. (2017). Pendalaman Pengetahuan Arsitektur Nusantara. Retrieved from http://repository.uki.ac.id/1387/

Wijayanti, G. ... Nurhasanah. (2019). Penerapan Balaksuji dan Langkan pada Rumah Tradisional Betawi di Kampung Betawi, Jakarta Selatan. Jurnal IImiah Mahasiswa Desain Interior: MEZANIN, 1(1). Retrieved from https://journal.untar.ac.id/index.php/meza nin/article/view/2952/1810

Yusoff, S. R. ... Kadir, R. A. (2010). The Role of Resort in Promoting Traditional Malay Architecture and Heritage Awareness Among Tourist in Malaysia. Arte-Polis 3 International Conference on Creative Collaboration and the Making of Place, 1-10. 
